\title{
Synthesis and application of a polymeric intumescent flame retardant for cotton fabric
}

\author{
FENGLING HAO $^{1}$, WEITAO GENG ${ }^{1}$, QUN LIU ${ }^{1}$, WEI DONG ${ }^{2}$, FAN-LONG JIN ${ }^{2}$ \\ and SOO-JIN PARK ${ }^{3, *}$ \\ ${ }^{1}$ Light Chemical Engineering, Jilin Institute of Chemical Technology, Jilin City 132022, People's Republic of China \\ ${ }^{2}$ Department of Polymer Materials, Jilin Institute of Chemical Technology, Jilin City 132022, People's Republic of China \\ ${ }^{3}$ Department of Chemistry, Inha University, Nam-gu, Incheon 402-751, South Korea \\ *Author for correspondence (sjpark@inha.ac.kr)
}

MS received 9 October 2018; accepted 9 April 2019

\begin{abstract}
A novel polymeric intumescent flame retardant containing phosphorus, nitrogen and sulphur (poly(ditrimethylolphosphono thiourea (PDTPT)) was synthesized, and its chemical structure was characterized by Fouriertransform infrared spectroscopy, ${ }^{1} \mathrm{H}$ and ${ }^{31} \mathrm{P}$ nuclear magnetic resonance spectroscopy and elemental analysis. The molecular weight and thermal properties of PDTPT were measured by using gel permeation chromatography and thermogravimetric analysis. PDTPT exhibited good thermal stability, char formation and swelling performance. The initial thermal decomposition temperature and quality residual rate at $600^{\circ} \mathrm{C}$ of PDTPT were $282^{\circ} \mathrm{C}$ and $48.8 \%$, respectively. When the mass fraction of PDTPT was $25 \mathrm{wt} \%$, the limiting oxygen index-value of the cotton fabric/PDTPT composite was 27 , an increase from 18 for the pure cotton fabric. Subsequent thermal analysis and scanning electron microscopy showed that PDTPT addition reduced the initial degradation temperature and the weight loss rate of the cotton fabric by forming a thick and tight carbon layer on its surface.
\end{abstract}

Keywords. Intumescent flame retardant; limiting oxygen index; nitrogen; phosphorus; thermal stability.

\section{Introduction}

Recently, halogen-containing flame retardants have been forbidden in many countries because they give off environmental pollution when they are burning. Therefore, intumescent flame retardants (IFRs), mainly containing phosphorus and nitrogen components, have been synthesized and applied to polymers. IFRs are more environmentally friendly than halogen-containing flame retardants because they release less smoke and fewer toxic products during combustion. A typical IFR mainly comprises an acid source, a carbonizing compound and a blowing agent [1-8].

Chen et al [9] and Wang et al [10] synthesized an IFR from pentaerythritol and melamine phosphate to prepare a flame-retardant polypropylene (PP) composite. They found that this IFR composed of small-molecule compounds which were easily attacked by water and migrated onto the surface of the PP matrix during extrusion, damaging the flame retardancy of PP. Therefore, polymeric IFRs have been developed and applied to polymers. Ma et al [11] synthesized a polymeric IFR, poly(4,4-diaminodiphenyl methane spirocyclic pentaerythritol bisphosphonate) (PDSPB), and indicated that the peak release rate was reduced by $58.3 \%$ for an acrylonitrile butadiene styrene (ABS)/PDSPB (30 wt \%) sample compared with that of the pure ABS resin. Ma et al [12-14] also investigated PDSPB covalently grafted onto the surfaces of multi-walled carbon nanotubes (MWCNTs; MWCNT-PDSPB) and prepared ABS/MWNTPDSPB nanocomposites via melt blending. The flammability of the nanocomposites was characterized by using a cone calorimeter. The flammability tests showed that better flame retardancy was obtained for the ABS/MWCNTPDSPB nanocomposites due to better dispersion of MWCNTPDSPB in the ABS matrix; this dispersion occurs because of hydrogen-bonding between the NH group in PDSPB and the ABS matrix. Hu et al [15] synthesized a polymeric IFR containing phosphorus and nitrogen (PSPTR). Their results showed that PSPTR-modified nylon exhibited high-flame retardancy with a B1 grade rating. PSPTR-modified cotton and polyester exhibited moderate flame retardancy with a B2 grade rating.

In this study, a novel polymeric IFR with a spiral structure, poly(ditrimethylolphosphono thiourea) (PDTPT), was synthesized and characterized by Fourier-transform infrared (FT-IR) spectroscopy, ${ }^{1} \mathrm{H}$ nuclear magnetic resonance (NMR) spectroscopy, ${ }^{31} \mathrm{P}$ NMR spectroscopy and elemental analysis. The molecular weight of PDTPT was determined by gel permeation chromatography (GPC) and the thermal properties of PDTPT were investigated by thermogravimetric analysis (TGA) and FT-IR spectroscopy. The influence of PDTPT addition on the flame-retardancy properties of cotton fabric was also investigated. 


\section{Experimental}

\subsection{Materials}

Ditrimethylolpropane (DTMP), phosphoryl chloride $\left(\mathrm{POCl}_{3}\right)$ and thiourea were obtained from PetroChina Jilin Petrochemical Co., Tianjin Fengchuan Chemical Reagent Co. and Tianjin Yongda Chemical Reagent Co., respectively. In addition, 1,2dichloroethane and acetonitrile were used as solvents and were purchased from Tianjin Ruijinte Chemicals Co. and Tianjin Yongda Chemical Reagent Co., respectively.

\subsection{Synthesis of spirocyclic ditrimethylolpropane diphosphoryl chloride (DTDC)}

DTMP (50 g, $0.2 \mathrm{~mol})$, 1,2-dichloroethane (100 g) and $\mathrm{POCl}_{3}$ $(67.45 \mathrm{~g}, 0.44 \mathrm{~mol})$ were mixed in a $250 \mathrm{ml}$ glass flask equipped with a circumference condenser and tail gas absorber. The mixture was heated to $40^{\circ} \mathrm{C}$ and allowed to react for $6 \mathrm{~h}$. Subsequently, 1,2-dichloroethane and unreacted $\mathrm{POCl}_{3}$ were removed by distillation under vacuum, ethanol $(50 \mathrm{ml})$ was added and the mixture was placed in a freezer $\left(-20^{\circ} \mathrm{C}\right)$ for $2 \mathrm{~h}$. After suction filtration, the resulting solid was dried at $70^{\circ} \mathrm{C}$ until a constant weight was achieved and a white powder was obtained (yield: $90 \%$ ).

\subsection{Synthesis of PDTPT}

DTDC $(50 \mathrm{~g}, 0.12 \mathrm{~mol})$ and thiourea $(11.1 \mathrm{~g}, 0.14 \mathrm{~mol})$ were added to a glass flask and dispersed in acetonitrile ( $100 \mathrm{~g})$. The mixture was stirred, gradually heated to $85^{\circ} \mathrm{C}$ and left to react for $6 \mathrm{~h}$ until $\mathrm{HCl}$ could no longer be detected. The product was added to ethanol $(50 \mathrm{ml})$ and dried to a constant weight in an oven at $120^{\circ} \mathrm{C}$ to afford a yellow crystalline solid in $89 \%$ yield.

\subsection{Preparation of a cotton fabric/PDTPT composite}

PDTPT $(400 \mathrm{~g})$ was added to distilled ethanol $(1000 \mathrm{ml})$ and stirred at $70^{\circ} \mathrm{C}$ for $30 \mathrm{~min}$. Cotton fabric with dimensions of
$58 \times 150 \mathrm{~mm}^{2}$ was immersed in the PDTPT solution enabling a wet pickup of $90-100 \%$. The PDTPT-treated cotton fabric was then dried at $80^{\circ} \mathrm{C}$ for $30 \mathrm{~min}$.

\subsection{Characterization and measurements}

FT-IR spectroscopy was performed with a Nicoylet-6700 FTIR spectrometer by using $\mathrm{KBr}$ pellets. ${ }^{1} \mathrm{H}$ NMR $(400 \mathrm{MHz})$ spectra were recorded on a Bruker $400 \mathrm{M}$ spectrometer in deuterated dimethylsulphoxide and ${ }^{31} \mathrm{P}$ NMR spectra were obtained by using a JNM-ECZ600R (600 MHz) solid-state NMR spectrometer.

The molecular weight of PDTPT was determined with a Waters-1515 GPC instrument in $N, N$-dimethylformamide. Elemental analysis of $\mathrm{C}, \mathrm{H}$ and $\mathrm{N}$ was performed using a Vario EL elemental analyser.

TGA was performed by using an SDT-Q600 thermal analyser at a scanning rate of $10^{\circ} \mathrm{C} \mathrm{min}^{-1}$ in air from 30 to $600^{\circ} \mathrm{C}$.

Limiting oxygen index (LOI) values were determined with a GT LOI2 oxygen index metre (Dongguan, China) according to GB/T 5454-1997. The sheet dimensions were $130 \times 6.5 \times$ $3.2 \mathrm{~mm}^{3}$.

The morphologies of the residual chars were investigated by using a JSM-6490LV instrument for scanning electron microscopy (SEM).

\section{Results and discussion}

\subsection{Synthesis of DTDC and PDTPT}

A schematic outline for the synthesis of the polymeric IFR is shown in figure 1 . The synthetic process consists of two major steps, esterification and polymerization. As illustrated in figure 1a, the hydroxy groups of DTMP reacted with $\mathrm{POCl}_{3}$ in 1,2-dichloroethane at $40^{\circ} \mathrm{C}$ to form DTDC, and a white powder was obtained in $90 \%$ yield. The polymeric IFR, PDTPT, was obtained by treating DTDC with thiourea at $85^{\circ} \mathrm{C}$ in acetonitrile as shown in figure $1 \mathrm{~b}$, to afford a yellow crystalline solid in $89 \%$ yield.<smiles>CCC(CO)(CO)COCC(CC)(CO)CO</smiles><smiles>CCC1(COCC2(CC)COP(=O)(Cl)OC2)COP(=O)(Cl)OC1</smiles>

(a)

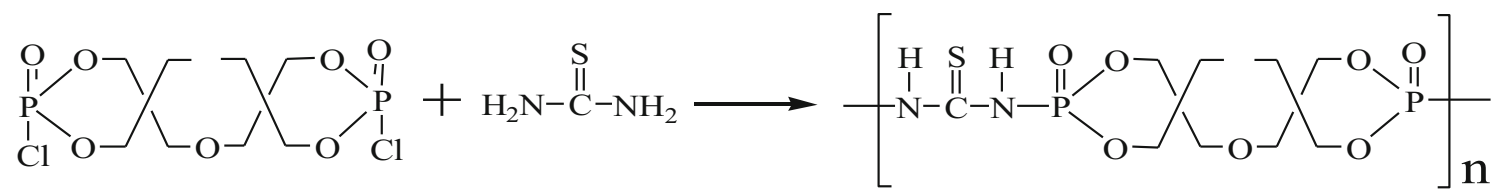

(b)

Figure 1. Schematic outline for the synthesis of polymeric IFR: (a) DTDC and (b) PDTPT. 


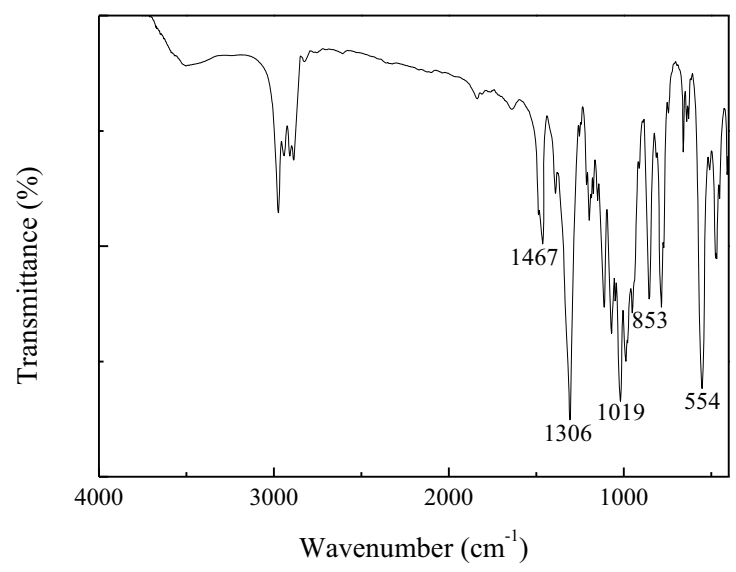

(a)

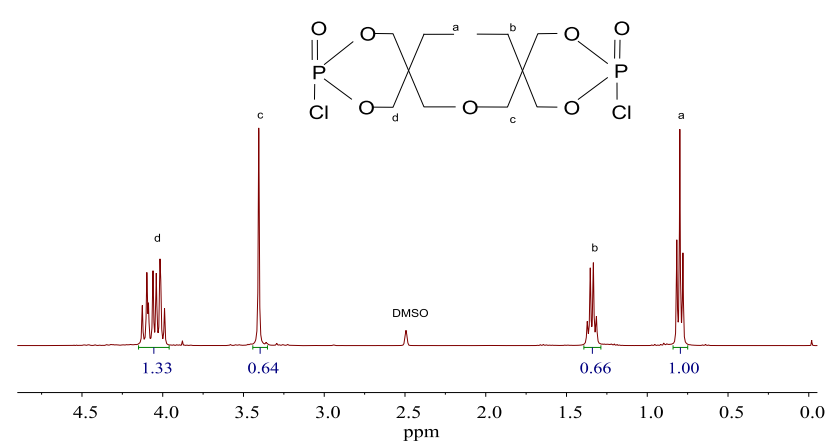

(b)

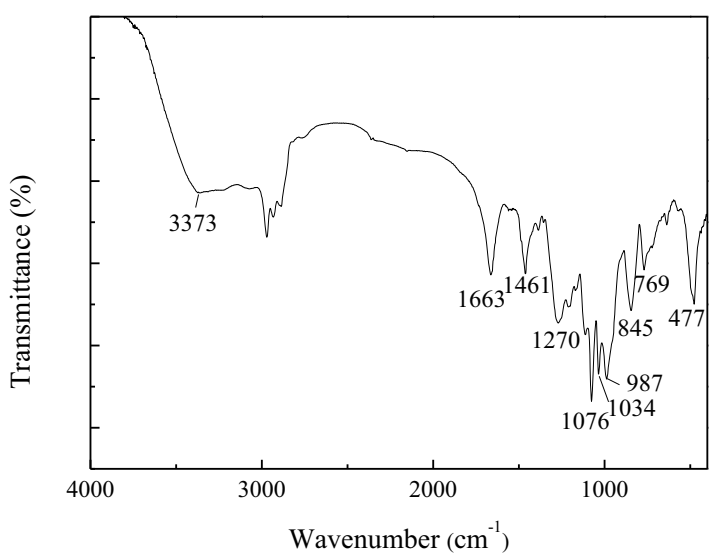

(a)

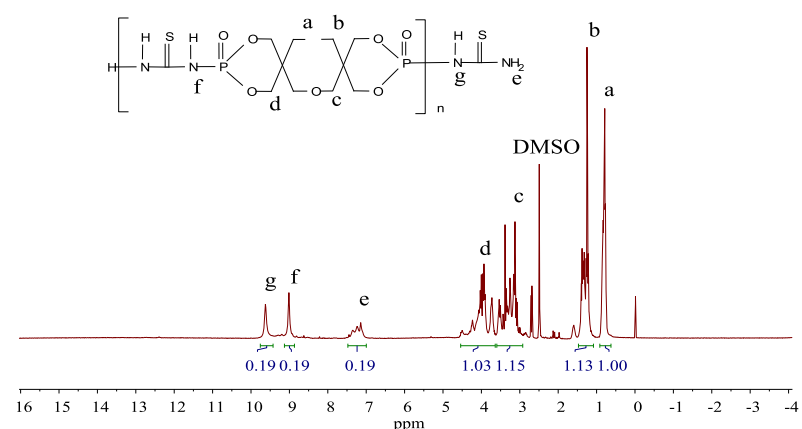

(b)

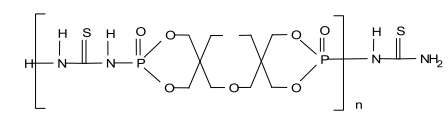

\begin{tabular}{lcccccccc}
\hline & \multicolumn{3}{c}{ Elemental analysis } & & \multicolumn{2}{c}{ Theoretical value } \\
\cline { 2 - 3 } Sample & $\mathrm{C}(\%)$ & $\mathrm{N}(\%)$ & $\mathrm{H}(\%)$ & & $\mathrm{C}(\%)$ & $\mathrm{N}(\%)$ & $\mathrm{H}(\%)$ \\
\hline DTDC & 35.13 & - & 5.50 & & 35.05 & - & 5.40 \\
PDTPT & 35.10 & 7.28 & 6.43 & & 36.72 & 8.08 & 5.82 \\
\hline
\end{tabular}

The chemical structure of DTDC was characterized by FT-IR spectroscopy, ${ }^{1} \mathrm{H}$ NMR spectroscopy and elemental analysis. Figure 2a shows the FT-IR spectrum of DTDC with significant bands at $1306 \mathrm{~cm}^{-1}(\mathrm{P}=\mathrm{O}), 1027$ and $1072 \mathrm{~cm}^{-1}$ $(\mathrm{P}-\mathrm{O}-\mathrm{C}), 853 \mathrm{~cm}^{-1}(\mathrm{P}-\mathrm{O})$ and $554 \mathrm{~cm}^{-1}(\mathrm{P}-\mathrm{Cl})$, indicating the successful reaction of DTMP with $\mathrm{POCl}_{3}$ [16-18]. Figure $2 b$ shows the ${ }^{1} \mathrm{H}$ NMR spectrum of DTDC with the peaks at $0.78-0.82 \mathrm{ppm}\left(-\mathrm{CH}_{3}\right), 1.32-1.37 \mathrm{ppm}\left(-\mathrm{CH}_{2}-\right)$, $3.40 \mathrm{ppm}\left(-\mathrm{CH}_{2}-\mathrm{O}-\mathrm{CH}_{2}-\right)$ and $3.99-4.13 \mathrm{ppm}\left(-\mathrm{CCH}_{2} \mathrm{O}-\right.$ PO-) confirming the structure of DTDC. From the integral peak area, the four peaks basically match a 3:2:2:4 ratio, indicating that the structural formula of the product matches that of the target compound [3,19-22]. Table 1 shows the elemental analysis results for DTDC with experimental values of $35.13 \% \mathrm{C}$ and $5.50 \% \mathrm{H}$. These values largely agree with the theoretical values for $\mathrm{C}(35.05 \%)$ and $\mathrm{H}(5.40 \%)$, providing

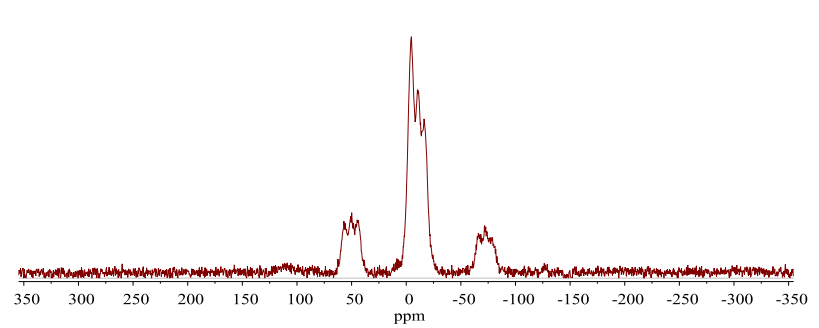

(c)

Figure 3. (a) FT-IR, (b) ${ }^{1} \mathrm{H}$ NMR and (c) ${ }^{31} \mathrm{P}$ NMR spectra of PDTPT.

strong evidence for the structure of DTDC [23]. Based on this characterization, the chemical structure of DTDC was confirmed in this study.

The chemical structure of PDTPT was characterized by FT-IR spectroscopy, ${ }^{1} \mathrm{H}$ and ${ }^{31} \mathrm{P}$ NMR spectroscopy and elemental analysis. The FT-IR spectrum of PDTPT is shown in figure 3a with significant peaks at $3373 \mathrm{~cm}^{-1}\left(-\mathrm{NH}_{2}\right)$, $1663 \mathrm{~cm}^{-1}(\mathrm{~N}-\mathrm{C}=\mathrm{S}), 1270 \mathrm{~cm}^{-1}(\mathrm{P}=\mathrm{O}), 1076$ and $1034 \mathrm{~cm}^{-1}$ 
Table 2. Molecular weight of PDTPT.

\begin{tabular}{ccccccc}
\hline Sample & $M_{\mathrm{n}}\left(\mathrm{g} \mathrm{mol}^{-1}\right)$ & $M_{\mathrm{w}}\left(\mathrm{g} \mathrm{mol}^{-1}\right)$ & $M_{\mathrm{p}}\left(\mathrm{g} \mathrm{mol}^{-1}\right)$ & $M_{\mathrm{z}}\left(\mathrm{g} \mathrm{mol}^{-1}\right)$ & $M_{\mathrm{z}}+1\left(\mathrm{~g} \mathrm{~mol}^{-1}\right)$ & $M_{\mathrm{w}} / M_{\mathrm{n}}$ \\
\hline PDTPT & 1827 & 1841 & 1781 & 1855 & 1869 & 1.0074 \\
\hline
\end{tabular}

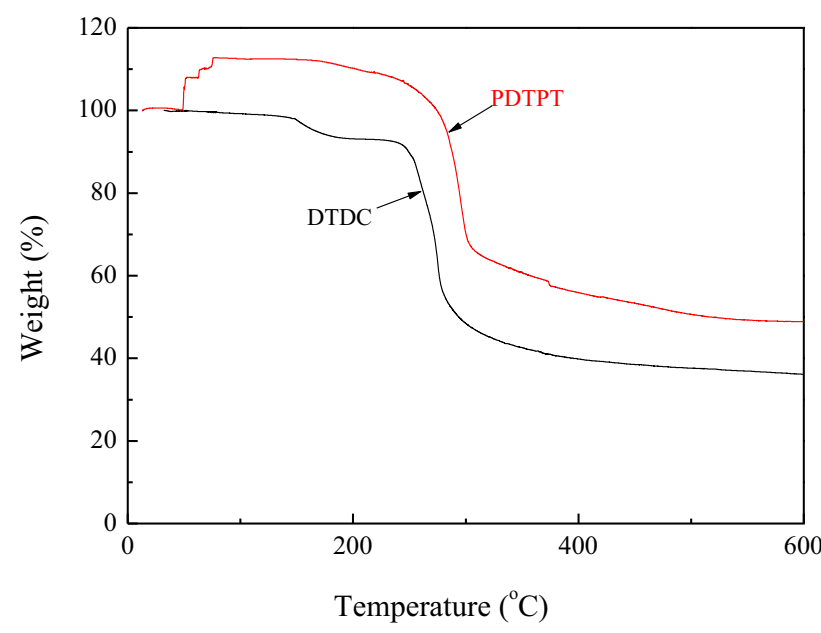

(a)

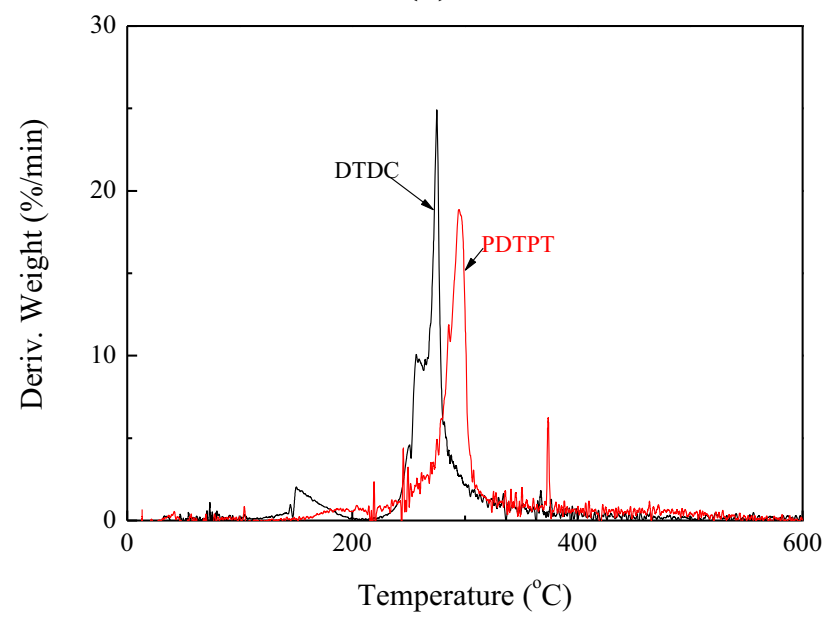

(b)

Figure 4. (a) TGA and (b) DTG thermograms of DTDC and PDTPT.

(P-O-C), $845 \mathrm{~cm}^{-1}(\mathrm{P}-\mathrm{O})$ and $987 \mathrm{~cm}^{-1}(\mathrm{P}-\mathrm{N})$. Moreover, the characteristic peak of the $\mathrm{P}-\mathrm{Cl}$ group was not observed, indicating that the polymerization reaction was complete [2427]. Figure $3 \mathrm{~b}$ shows the ${ }^{1} \mathrm{H}$ NMR spectrum of PDTPT with new peaks at 7.14-7.35 ppm $\left(-\mathrm{NH}_{2}\right), 8.87-9.13 \mathrm{ppm}$ (P-NH-) and 9.44-9.74 ppm (P-NH- connected with - CS$\mathrm{NH}_{2}$ ). Figure $3 \mathrm{c}$ shows the ${ }^{31} \mathrm{P}$ NMR spectrum of PDTPT with a broad peak comprising two symmetric sidebands at $-10 \mathrm{ppm}$ [28-31]. The results of the elemental analysis for PDTPT are shown in table 1 . The values for $\mathrm{C}(35.10 \%)$,
Table 3. Thermal stability factors of DTDC and PDTPT obtained from TGA and DTG thermograms.

\begin{tabular}{lcccc}
\hline Sample & $T_{5 \%}\left({ }^{\circ} \mathrm{C}\right)$ & $T_{50 \%}\left({ }^{\circ} \mathrm{C}\right)$ & $T_{\max }\left({ }^{\circ} \mathrm{C}\right)$ & $\begin{array}{c}\text { Char at } 600{ }^{\circ} \mathrm{C} \\
(\mathrm{wt} \%)\end{array}$ \\
\hline DTDC & 170 & 290 & 275 & 36.1 \\
PDTPT & 282 & 520 & 295 & 48.8 \\
\hline
\end{tabular}

$\mathrm{H}(6.43 \%)$ and $\mathrm{N}(7.28 \%)$ were close to the theoretical values of $\mathrm{C}(36.72 \%), \mathrm{H}(5.82 \%)$ and $\mathrm{N}(8.08 \%)$, providing strong evidence for the structure of PDTPT [32]. Through this characterization, the chemical structure of PDTPT was confirmed.

The degree of polymerization of PDTPT was calculated from the peak area values of the $\mathrm{P}-\mathrm{NH}-$ and $-\mathrm{NH}_{2}$ peaks in ${ }^{1} \mathrm{H}$ NMR spectra. The ratio of the peak areas for $\mathrm{P}-\mathrm{NH}-$ to $-\mathrm{NH}_{2}$ is two, indicating that the degree of polymerization is $\sim 4$ and the molecular weight is $\sim 1734 \mathrm{~g} \mathrm{~mol}^{-1}$ [33]. Table 2 shows the molecular weight of PDTPT as measured by GPC: the peak molecular weight, $M_{\mathrm{p}}$, was $1781 \mathrm{~g} \mathrm{~mol}^{-1}$ and the calculated degree of polymerization was $\sim 4$, which was the same as the value calculated from the ${ }^{1} \mathrm{H}$ NMR spectrum. In addition, the polydispersity index, $M_{\mathrm{w}} / M_{\mathrm{n}}$, is close to one, indicating that the molecular weight distribution was narrow and confirming that PDTPT was successfully synthesized and exhibited a relatively stable degree of polymerization.

\subsection{Thermal stability}

Figure 4 shows the TGA and differential thermal gravimetric (DTG) thermograms of DTDC and PDTPT. Thermal stability factors, such as the initial decomposition temperature (the temperature of $5 \%$ weight loss, $T_{5 \%}$ ), temperature at $50 \mathrm{wt} \%$ weight loss $\left(T_{50 \%}\right)$, temperature at the maximum weight loss rate $\left(T_{\max }\right)$ and char formation at $600^{\circ} \mathrm{C}$ were calculated from the TGA thermograms [34-36]. The thermal stability factors are shown in table 3 .

The thermal stability factors of PDTPT are higher than those of DTDC. PDTPT starts decomposing at $282^{\circ} \mathrm{C}$ with a residue of $48.8 \%$ at $600^{\circ} \mathrm{C}$ in air, which indicates that PDTPT is an efficient charforming agent. The DTG result showed that PDTPT has minor (at $\sim 250^{\circ} \mathrm{C}$ ) and major (at $\sim 295^{\circ} \mathrm{C}$ ) weight loss stages, which were attributed to scission of the phosphate ester bonds and intumescent char formation, respectively 


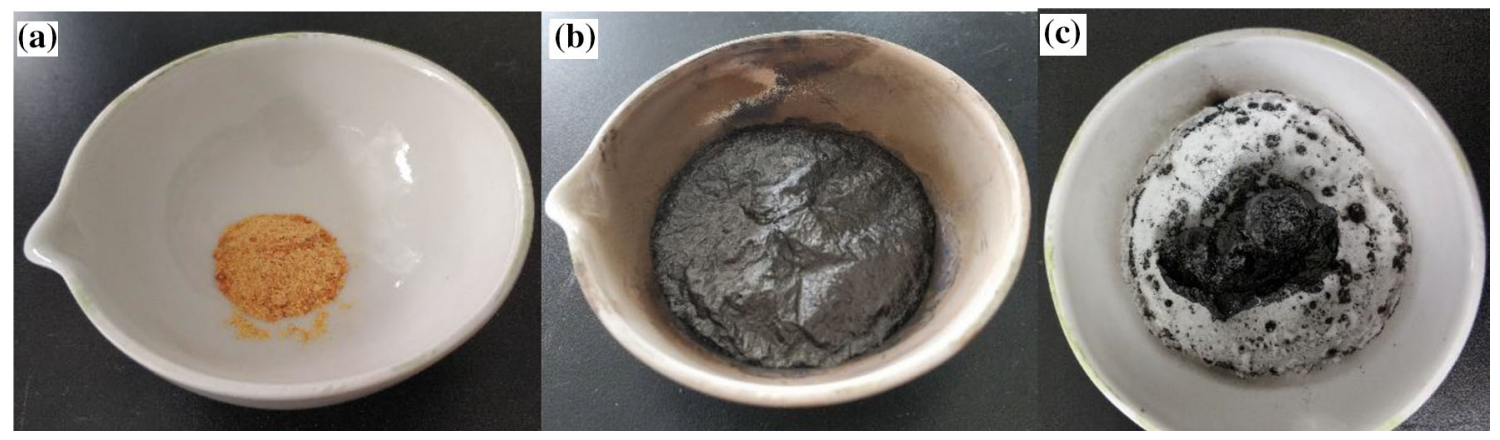

Figure 5. Digital photos of residues of PDTPT at: (a) room temperature; (b) $300^{\circ} \mathrm{C}$ for 30 min and (c) $500^{\circ} \mathrm{C}$ for $30 \mathrm{~min}$.

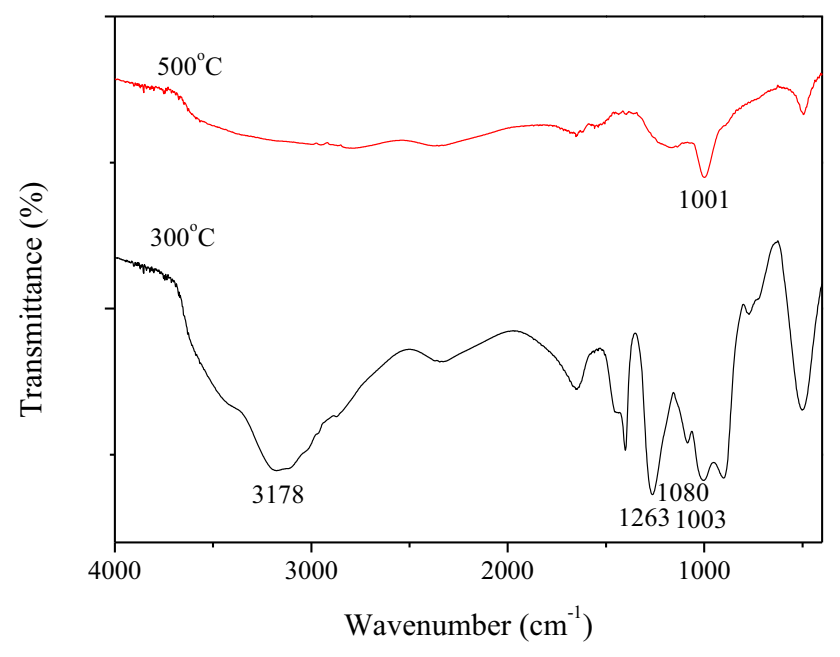

Figure 6. FT-IR spectra of residual char of PDTPT obtained after heating at 300 and $500^{\circ} \mathrm{C}$ for $30 \mathrm{~min}$ in air.

[37,38]. Thus, PDTPT has high enough thermal stability to satisfy the processing temperature requirements of most polymers.

To determine the effects of the formation of intumescent char on the combustion of PDTPT, the structure of the residues left after combustion was investigated by using FT-IR spectroscopy and the morphologies were examined by optical photography with a digital camera. Figure $5 \mathrm{a}$ and $\mathrm{b}$ show the morphologies of PDTPT before and after heating at $300^{\circ} \mathrm{C}$ for $30 \mathrm{~min}$. The PDTPT degraded and rapidly expanded upon heating to form a thick and rigid carbon layer. Figure $5 \mathrm{c}$ shows the morphology of PDTPT after heating at $500^{\circ} \mathrm{C}$ for $30 \mathrm{~min}$. The PDTPT decomposed and residual carbon was primarily found, indicating that PDTPT forms an excellent residual char at high temperatures $[39,40]$.

Figure 6 shows the FT-IR spectra of the intumescent residual char of PDTPT after heating at 300 and $500^{\circ} \mathrm{C}$ for $30 \mathrm{~min}$. The broad peaks at $3178-1263 \mathrm{~cm}^{-1}$ were assigned to the stretching vibrations of $\mathrm{P}-\mathrm{O}$ and $\mathrm{P}=\mathrm{O}$ groups. The absorption peaks of the symmetric stretching vibrations of
P-O-C were observed at 1080 and $1003 \mathrm{~cm}^{-1}$. These results indicate that PDTPT generates phosphoric acid during thermal degradation.

\subsection{Flame-retardancy properties}

The flame-retardancy properties of a cotton fabric and the cotton fabric/PDTPT (25 wt $\%$ ) composite were investigated by LOI analysis. The LOI is one of the most commonly used parameters to indicate the flammability of textiles and polymer materials. Generally, if the LOI value of cotton fabrics is less than or equal to $22 \%$, the cotton fabrics are called flammable materials. If the LOI value of cotton fabrics is between 22 and $27 \%$, the cotton fabrics are called combustible material. If the LOI value of cotton fabrics is greater than or equal to $27 \%$, the cotton fabrics are called flame-retardant materials [41]. The LOI value of the original cotton fabric was 18 , indicating its inherent flammability. The LOI value of the cotton/PDTPT composite was 27, suggesting that PDTPT is a good flame retardant for the cotton fabric.

Figure 7 shows the TGA and DTG thermograms of the cotton fabric and the cotton fabric/PDTPT composite and the thermal stability factors are listed in table 4 . The cotton fabric exhibited only one decomposition step at $300-380^{\circ} \mathrm{C}$ and negligible amounts of carbon remained above $500^{\circ} \mathrm{C}$. As shown in table 4, PDTPT reduces the initial degradation temperature and weight loss rate of the cotton fabric. The $T_{5 \%}, T_{50 \%}$ and $T_{\max }$ values of the composite were smaller than those of the pure cotton fabric. The value of the carbon residue for the composite at $600^{\circ} \mathrm{C}$ is much larger than that for the pure cotton fabric. These results indicate that PDTPT degraded and produced phosphoric acid, accelerating the esterification and carbonization reactions and effectively protecting the cotton fabric [42].

Figure 8 shows photographs of the pure cotton fabric and the cotton fabric/PDTPT composite before and after flame testing. As shown in figure $8 \mathrm{c}$, the pure cotton fabric burn completely. However, the cotton fabric/PDTPT composite did not burn as shown in figure 8d. The burning times after ignition for the pure cotton fabric and the cotton 
Table 4. Thermal stability factors of the cotton fabric and cotton fabric/PDTPT composite obtained from TGA and DTG thermograms.

\begin{tabular}{lcccc}
\hline Sample & $T_{5 \%}\left({ }^{\circ} \mathrm{C}\right)$ & $T_{50 \%}\left({ }^{\circ} \mathrm{C}\right)$ & $T_{\max }\left({ }^{\circ} \mathrm{C}\right)$ & Char at $600{ }^{\circ} \mathrm{C}(\mathrm{wt} \%)$ \\
\hline Cotton fabric & 256 & 373 & 379 & 5.5 \\
Cotton fabric/25wt\% PDTPT & 206 & 336 & 260 & 32.2 \\
\hline
\end{tabular}

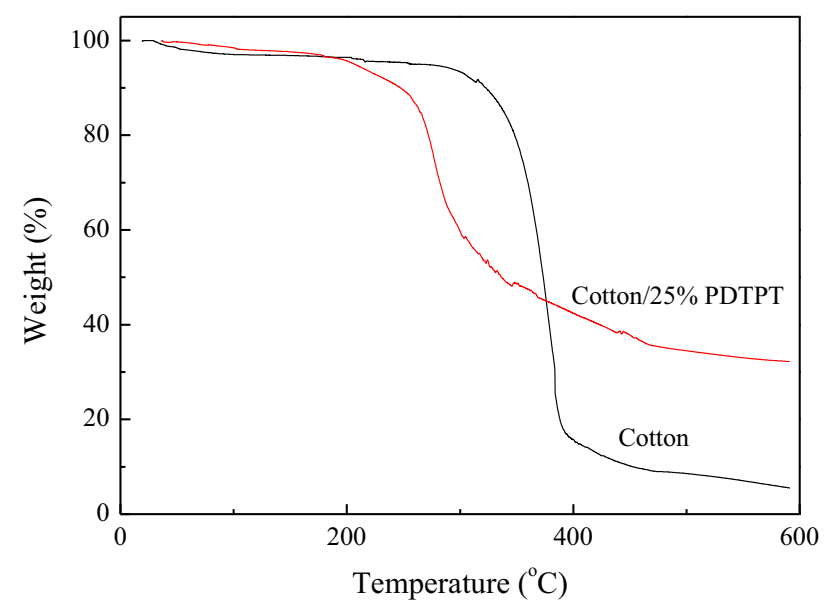

(a)

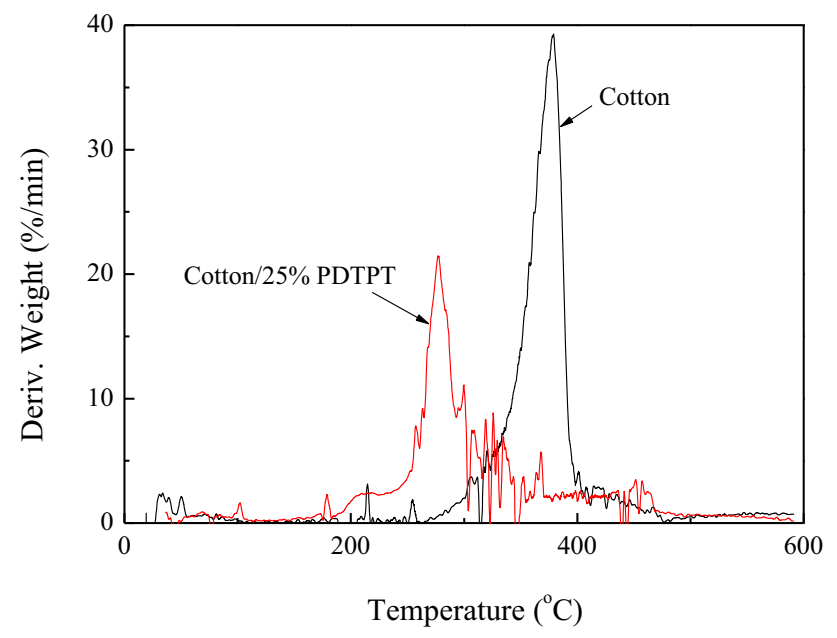

(b)

Figure 7. (a) TGA and (b) DTG thermograms of the cotton fabric and cotton fabric/PDTPT composite.

fabric/PDTPT composite are 30 and $1 \mathrm{~s}$, respectively, which indicates that PDTPT is a good flame retardant for the cotton fabric.

Figure 9 shows the SEM micrographs of the combustion residues of the cotton fabric and the cotton fabric/PDTPT composite. As shown in figure 9a1-a4, the pure cotton fabric residue appears pale grey after burning and is very sparse with

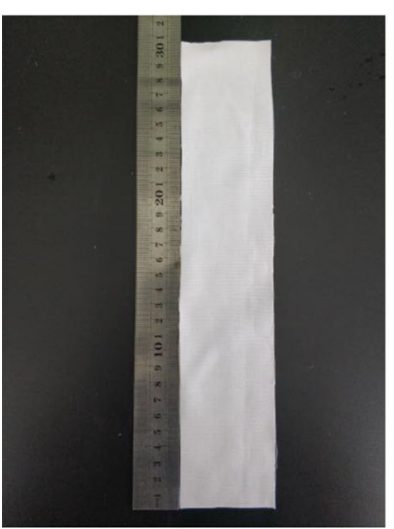

(a)

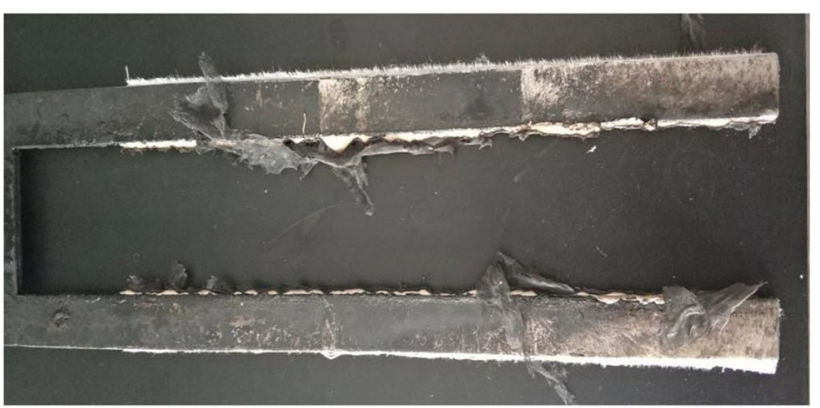

(c)

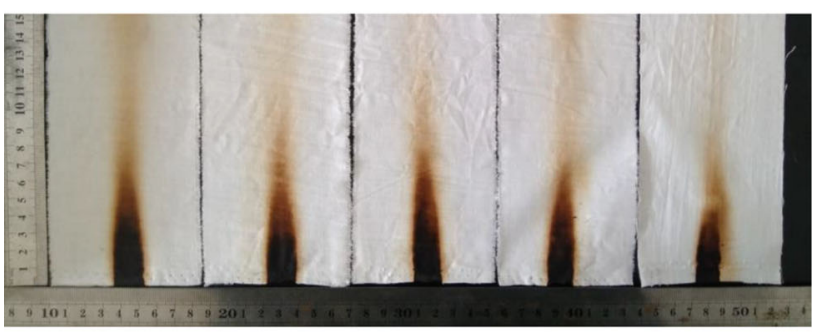

(d)

Figure 8. Photographs of (a) pure cotton fabric and (b) cotton fabric/PDTPT composite before flame testing. Photographs of (c) pure cotton fabric and (d) cotton fabric/PDTPT composite after flame testing.

little carbon residue; this indicates difficulty in the formation of char layers. The PDTPT treated cotton fabric residue was dark black after burning and was quite dense and expansive as shown in figure 9b1-b4. The dense carbon layer acts as a barrier and slows agglomeration during the combustion process. The exchange of matter and heat between the solid 

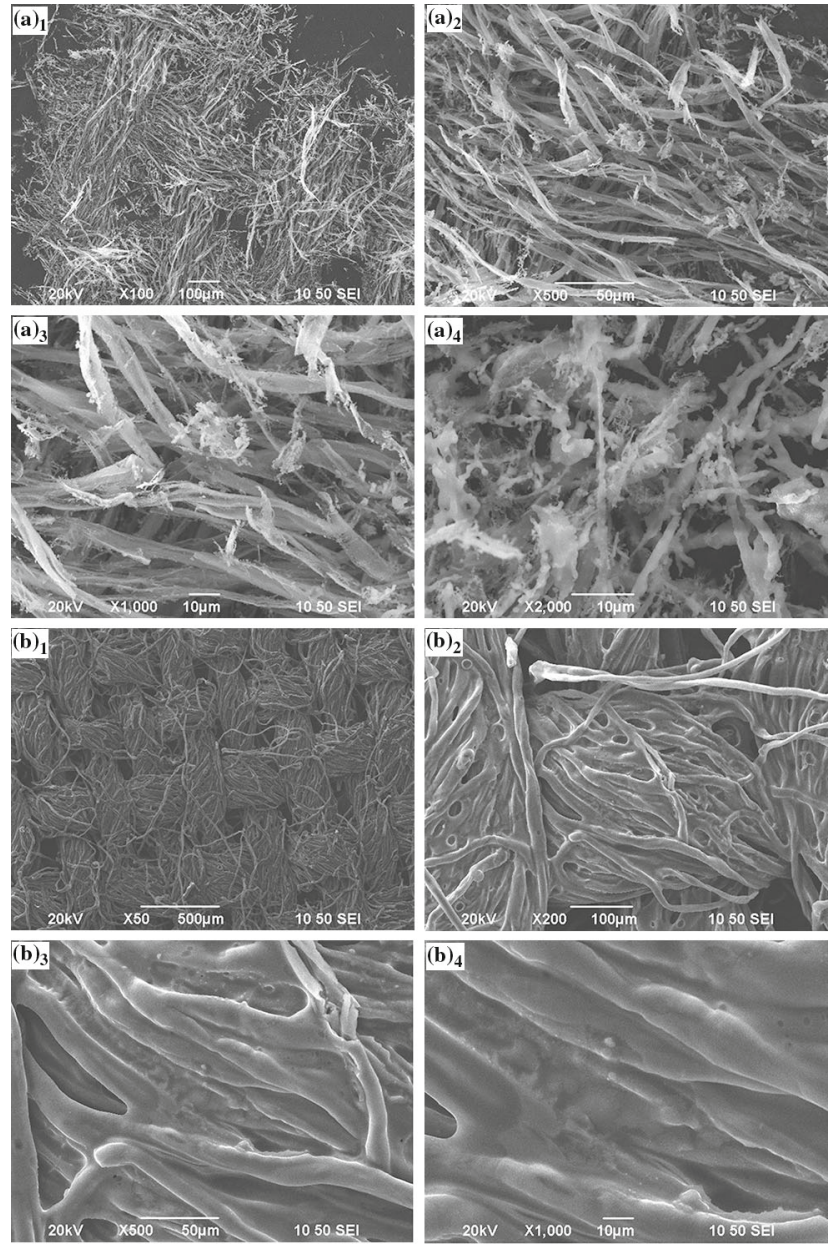

Figure 9. SEM micrographs of combustion residues: (a1) 100 $\times$, (a2) $500 \times$, (a3) $1000 \times$ and (a4) $2000 \times$ : pure cotton fabric and (b1) $100 \times$, (b2) $500 \times$, (b3) $1000 \times$ and (b4) $2000 \times$ : cotton fabric/PDTPT composite.

and gas phases prevents degradation of the internal cotton fabric $[43,44]$. Moreover, it is clear from the image that the matrix is tightly wrapped by the carbon layer formed by PDTPT degradation, indicating that the PDTPT and cotton fabric are closely and firmly bonded.

\section{Conclusions}

A novel polymeric IFR, PDTPT, was synthesized and its chemical structure was characterized. The degree of polymerization of PDTPT was four and its molecular weight was $1781 \mathrm{~g} \mathrm{~mol}^{-1}$. PDTPT exhibited excellent swelling performance, high-thermal stability and good char formation. The initial decomposition temperature of PDTPT is $282^{\circ} \mathrm{C}$, which can meet the processing temperature requirements for most products. The LOI value of the cotton fabric/PDTPT composite increased from 18 for the pure cotton fabric to 27 when the PDTPT content was increased to $25 \mathrm{wt} \%$, indicating that PDTPT exhibited excellent flame-retardancy properties. The TGA results showed that the addition of PDTPT reduced the initial degradation temperature and weight loss rate of the cotton fabric. The SEM results showed that the PDTPT was tightly attached to the cotton fabric and that a thick and compact char layer was formed on the surface of the cotton fabric, effectively preventing the cotton fabric from burning.

\section{References}

[1] Khanal S, Zhang W, Ahmed S, Ali M and Xu S 2018 Compos. A 112444

[2] Lu C, Gao X, Yao D, Cao C and Luo Y 2018 Polym. Degrad. Stab. 15375

[3] Zhu C, He M, Liu Y, Cui J, Tai Q, Song L et al 2018 Polym. Degrad. Stab. 151144

[4] Xu L, Lei C, Xu R, Zhang X and Xu J 2018 Polym. Bull. 75 2707

[5] Tang Y, Hu Y, Wang S F, Gui Z, Chen Z Y and Fan W C 2010 Polym. Int. 521396

[6] Singh K P, Mishra A, Kumar N, Tripathi D N and Shami T C 2018 Polym. Bull. 752415

[7] Hassan M, Nour M, Abdelmonem $Y$, Makhlouf $G$ and Abdelkhalik A 2016 Polym. Degrad. Stab. 1338

[8] Manfredi A, Carosio F, Ferruti P, Ranucci E and Alongi J 2018 Polym. Degrad. Stab. 15152

[9] Chen Y H, Liu Y, Wang Q, Yin H, Aelmans N and Kierkels R 2003 Polym. Degrad. Stab. 81215

[10] Wang Q, Chen Y H, Liu Y, Yin H, Aelmans N and Kierkeis R 2004 Polym. Int. 53439

[11] Ma H Y, Tong L F, Xu Z B, Fang Z P, Jin Y M and Lu F Z 2007 Polym. Degrad. Stab. 92720

[12] Ma H Y, Tong L F, Xu Z B and Fang Z P 2008 Adv. Funct. Mater. 18414

[13] Ma H Y and Fang Z P 2012 Thermochim. Acta 543130

[14] Ma H Y, Tong L F, Xu Z B and Fang Z P 2008 Appl. Clay Sci. 42238

[15] Hu X P, Guo Y Y, Chen L and Wang Y Z 2012 Polym. Degrad. Stab. 971772

[16] Zhao J, Xie T and Qin J 2018 Plast. Sci. Technol. 2107

[17] Luo C, Zuo J, Wang F, Yuan Y, Lin F and Zhao J 2018 Macromol. Res. 26346

[18] Jin F L, Liu H C, Yang B and Park S J 2015 J. Ind. Eng. Chem. 2420

[19] Wang C, Wu Y C, Li Y C, Shao Q, Yan X R, Han C et al 2018 Polym. Adv. Technol. 29668

[20] Wang X Y, Li Y, Liao W W, Gu J and Li D 2008 Polym. Adv. Technol. 191055

[21] Li B, Zhan Z S, Zhang H F and Sun C Y 2014 J. Vinyl Addit. Technol. 2010

[22] Kim W, Hoang D Q, Vothi H, Nguyen C, Giang T, An H et al 2016 Macromol. Res. 2466

[23] Makhlouf G, Hassan M A, Nour M A, Abdelmonem Y and Abdelkhalik A 2017 Arab. J. Sci. Eng. 424339

[24] Jimenez M, Duquesne S and Bourbigot S 2006 Ind. Eng. Chem. Res. $\mathbf{4 5} 4500$ 
[25] Kandola B and Krishnan L 2014 Fire Safety Sci. 11769

[26] Zhang J, Li D G, Fu M, Zhang Y L, Zhang L P and Zhao P P 2016 J. Vinyl Addit. Technol. 22293

[27] Jiang W, Jin F L and Park S J 2015 J. Ind. Eng. Chem. 2740

[28] Ding X, Fang F, Du T X, Zheng K, Chen L and Zhang X 2016 Surf. Coat. Technol. 305184

[29] Hu G J, Zhao C G, Zhang S M, Yang M S and Wang Z Y 2006 Polymer 47480

[30] Xie F, Wang Y Z, Yang B and Liu Y 2010 Macromol. Mater. Eng. 291247

[31] Bourbigot S, Bras M L, Delobel R and Gengembre L 1997 Appl. Surf. Sci. 12015

[32] Cai Y B, Hu Y, Song L, Xuan S Y, Zhang Y, Chen Z Y et al 2007 Polym. Degrad. Stab. 92490

[33] Chen H, Wang J H, Ni A Q, Ding A X, Han X and Sun Z H 2018 Materials 112

[34] Yao S S, Pang Q Q, Song R, Jin F L and Park S J 2016 Macromol. Res. 24961
[35] Xu H J, Jin F L and Park S J 2009 Bull. Korean Chem. Soc. 30 2643

[36] Chen J L, Jin F L and Park S J 2010 Macromol. Res. 18862

[37] Chen C K, Zhao X L, Shi C L and Chen J 2018 J. Mater. Sci. 536053

[38] Su X Q, Yi Y W, Tao J, Qi H Q and Li D Y 2014 Polym. Degrad. Stab. 10512

[39] Lai X J, Qiu J D, Li H Q, Zhou R M, Xie H L and Zeng X R 2016 J. Anal. Appl. Pyrol. 120361

[40] Xu Z Z, Huang J Q, Chen M J, Tan Y and Wang Y Z 2013 Polym. Degrad. Stab. 982011

[41] Wu W and Yang C Q 2003 J. Appl. Polym. Sci. 901885

[42] Xie H L, Lai X J, Li H Q and Zeng X R 2016 Polym. Degrad. Stab. 13068

[43] Wen P, Feng X, Kan Y, Hu Y and Yuen R K K 2016 Polym. Degrad. Stab. 134202

[44] Ma H, Wang J and Fang Z 2012 Polym. Degrad. Stab. 97 1596 